\title{
Evaluation of Various Modalities of Surgical Treatment of Distal End Radius Fractures in a Tertiary Hospital in Bangalore
}

\section{Yogesh, Anil Chowdary*, Ambreesh, Arvind JD, Yashwant and Sneha}

Department of Orthopaedics, Vydehi Institute of Medical Sciences and Research Centre, Bangalore, India

*Corresponding Author: Anil Chowdary, PG Scholar, Department of Orthopaedics, Vydehi Institute of Medical Sciences and Research Centre, Bangalore, India.

DOI: 10.31080/ASOR.2022.05.0431
Received: January 31, 2022

Published: February 25, 2022

(C) All rights are reserved by Anil Chowdary., et al.

\begin{abstract}
The fracture of the distal radius is the most common fracture encountered in daily practice. Besides, these fractures are also reported in elderly osteoporotic patients. If these fractures are not assessed properly and not treated on time, angulation, shortening and articular incongruity may lead to permanent deformity and loss of function. The degree of disability is highly correlates with degree of residual deformity in elderly patients. There is no consensus with regards to the optimal management of these fractures and lack of scientific evidence to allow definitive conclusions concerning the main aspects of managing distal radius fractures. In this context of the research gap, the present study was undertaken to compare the functional outcome of treatment fracture distal end radius with various surgical modalities i.e. closed reduction and percutaneous K-wire fixation under C-arm guidance with post op cast immobilization, Ligament taxis and stabilization with external fixator, Open reduction and internal fixation with Dynamic Compression Plates, Locking Compression Plates and Buttress Locking Compression Plate. The Mean age of patients was 37.21 years. 48 (82.75\%) males and 6 (10.34\%) females were considered for the study. Left side was involved in 28 cases (48.27\%), right in 22 cases (37.93\%), 4 (6.89\%) patients had both wrist fractures. Using AO classification, study shows better outcome with plating or $\mathrm{k}$ wiring for $\mathrm{A}_{2}$ type of fractures, $\mathrm{K}$ wiring or Ex Fix for type $\mathrm{A}_{3}$, Plating for $\mathrm{B}_{1}, \mathrm{~B}_{2}, \mathrm{~B}_{3}, \mathrm{C}_{1}$ type, External fixation for $\mathrm{C}_{2}$ type, Plating or Ex fix+ $\mathrm{k}$ wiring + Plating is preferred for $\mathrm{C}_{3}$ type. The functional outcome after fixation of distal radius fractures depends on patient's age, fracture anatomy, displacement, reducibility, stability and articular incongruity of fractures. They are related more to the quality of anatomical reduction than to the method of immobilization. Volar locking plates are safe and effective option for unstable fracture types.
\end{abstract}

Keywords: Distal Radius; Comminuted; Intra Articular; Open Reduction; Internal Fixation; External Fixation

\section{Introduction}

The distal radial joint anatomical restoration is the rationale for operative treatment. Most of the studies associated as little as $1 \mathrm{~mm}$ of incongruity of the distal radius articular surface with worse outcomes, whereas some studies report have found no association of radiographic arthrosis and outcomes. The degree of articular surface displacement and disruption, the stability and reducibility of each fracture, as well as any concurrent injury to adjacent nerves, tendons or carpal structures must be assessed carefully in logical treatment planning $[1,2,5,6]$. The optimal man- agement aims at accurate skeletal anatomy restoration by closed or open treatment, recognition and repair of associated injuries and supervised rehabilitation by skilled therapists $[6,7,9]$. Even though 1000 peer-reviewed published studies on distal radius fractures management, still there is no consensus on which treatment are superior or firm guidelines regarding treatment decisions $[4,5]$. Many confounding variables exist, which are somewhat controversial: like level of anatomical restoration, quality of the bone, the advances in techniques and devices, the experience and ability of the surgeon and outcomes in elderly populations $[10,11]$. Bimodal 
age distribution gives different outcomes, multiple reports indicate that older, low demand patients tend to tolerate incongruity, deformity, and malunion well compared to younger age group [1214]. Madhok., et al. noted that in $26 \%$ elderly patients treated conservatively reported functional impairment [15-17]. Basically, we know that elderly patients will withstand more displacement (and closed treatment) compared to younger patients, but still few have poor results. Interestingly, despite malunion of fracture, many aged patients function quite well, but the majority of studies showing acceptable function in elderly patients who were frail or had low functional demands [6]. Distal End Radius fracture is mostly comminuted in nature, which is responsible for non-maintenance of reduction, which is a common late, finding [18-20]. Distal radius fracture possesses little or no stability following closed reduction and can go on for gradual collapse [21,22]. Hence, basic principles of management are:(i) Stable reduction of displaced fractures (ii) Maintenance of reduction during healing (iii) Early functional rehabilitation of the limb.In present study, we aimed to correlate the functional outcomes of treatment of distal end radius fractures with various surgical modalities i.e. closed reduction and percutaneous K-wire fixation under fluoroscopic guidance with postop cast immobilization, ligamentotaxis and stabilization with external fixator, open reduction and internal fixation with dynamic compression plate, locking compression plates and buttress locking compression plate.

\section{Materials and Methods}

Total of 54 patients with 58 wrists of distal radius fracture admitted in Vydehi Institute of Medical Sciences and Research Centre, Bangalore during January, 2019 to June, 2020. All cases were taken into study after seeing inclusion criteria, the Patients aged more than 18 years both male and female with Fracture of distal end radius of either side or both, with or without ulnar fractures and undergoing surgery for same and giving informed consent for participation in this study. Unstable, comminuted or intra articular fracture and Fractures up to $3 \mathrm{~cm}$ from distal articular surface of radius. The detailed history, clinical examination, preoperative X-rays and relevant investigations were done as per hospital protocol. Distal radius fractures were classified according to AO classification and appropriate surgical management was chosen by treating surgeon. Postoperative $\mathrm{x}$ rays taken and patient followed up regularly till one year and functional outcome was assessed by Demerit scoring system. Exclusion Criteria; Patient with distal radius fracture undergoing conservative management or not giving consent for participation in this study. Congenital deformity of radius and Patients medically unfit or not willing for surgery. All cases underwent detailed clinical examination followed by preoperative x-ray and relevant investigations as per hospital protocol. The fracture was considered to be united or healed, when clinically there was no.

Tenderness or subjective complaints and radiologically when the fracture line was not visible. Fractures which healed by 4-6 months without an additional operative procedure were considered as delayed union. Fractures which did not unite after 6 months orthose that needed additional operative procedure to unite were considered as non-union. The ANOVA test with post-hoc Tukey"s used for analysing quantitative data and non-parametric data was analysed by Kruskal Wall"s test.

\section{Results}

The mean age of the patients was 37.21 years with SD 1.33 years. Half (55.6\%) of the cases were of 40 years or below. Male was predominant (88.9\%) as compared with female (11\%).Sex ratio was ratio of 8:1. Affected Sides were recorded; the left side was affected in (51.9\%) cases while right side was affected in (40.7\%) cases. In 4 cases (7.4\%), both wrists were affected. Most common mode of injury was road traffic accidents (57.4\%) then followed by fall on outstretched hand (42.6\%). Out of the 58 cases, 25 cases $(43.1 \%)$ were intra-articular fractures (AO type $A_{2} / A_{3}$ ) while 18 cases $(31 \%)$ were of extra-articular fractures (AO type $C_{1}-C_{3}$ ). Total of $(91.4 \%)$ were closed fractures while (8.6\%) were open Fractures. Associated injuries were seen in about a third of the cases (29.6\%). Most common among them were: ulnar fracture (9.3\%), scaphoid fracture (7.4\%) and humerus fracture (3.7\%).A total of $58.6 \%$ cases were managed by plating, (22.4\%) with closed reduction and K-wiring while external fixation with or without plating/ K-wire was required in (19\%) cases.

Table 1 shows that, the management details among various fracture types. Most of the intra-articular fractures were managed by plating or K-wire while in partially articular fractures $13(34.21 \%$, odds $3.22 \mathrm{p}<0.001)$, plating was preferred $34(89.47 \%$, odds 6.58 $\mathrm{p}<0.01$ ). External fixation with or without plating/wiring was re- 


\begin{tabular}{|c|c|c|c|c|c|c|c|}
\hline \multirow[b]{2}{*}{ O Type Treatment } & \multicolumn{5}{|c|}{ Treatment } & \multirow[b]{2}{*}{ Total } & \multirow[b]{2}{*}{ P-value } \\
\hline & Plating & K-wiring & External fixation & $\begin{array}{c}\text { Ex Fix+ } \\
\text { K-wiring }\end{array}$ & $\begin{array}{c}\text { Ex Fix+ } \\
\text { Kwiring + } \\
\text { Plating }\end{array}$ & & \\
\hline $\mathrm{A}_{2}$ & 11 & 7 & 0 & 0 & 0 & $18(31.03 \%)$ & $<0.001$ \\
\hline $\mathrm{A}_{3}$ & 4 & 2 & 2 & 0 & 0 & $8(13.79 \%)$ & $<0.001$ \\
\hline $\mathrm{B}_{1}$ & 4 & 1 & 0 & 0 & 0 & $5(8.62 \%)$ & $<0.001$ \\
\hline $\mathrm{B}_{2}$ & 4 & 0 & 0 & 0 & 0 & $4(6.89 \%)$ & $<0.001$ \\
\hline $\mathrm{B}_{3}$ & 6 & 0 & 0 & 1 & 0 & $7(12.06 \%)$ & $<0.001$ \\
\hline $\mathrm{C}_{1}$ & 2 & 2 & 0 & 1 & 0 & $5(8.62 \%)$ & $<0.001$ \\
\hline $\mathrm{C}_{2}$ & 2 & 1 & 4 & 0 & 1 & $8(13.79 \%)$ & $<0.001$ \\
\hline $\mathrm{C}_{3}$ & 1 & 0 & 1 & 0 & 1 & $3(5.17 \%)$ & $<0.001$ \\
\hline Total & $34(89.47 \%)$ & $13(34.21 \%)$ & $7(18.42 \%)$ & $2(5.26 \%)$ & $2(5.26 \%)$ & $58(100 \%)$ & \\
\hline Odds & $\begin{array}{c}6.58 \\
(<0.001)\end{array}$ & $\begin{array}{c}3.22 \\
(<0.001)\end{array}$ & $\begin{array}{c}2.85 \\
(<0.001)\end{array}$ & $<1(>0.01)$ & $\begin{array}{c}<1 \\
(>0.01)\end{array}$ & & \\
\hline
\end{tabular}

Table 1: Association of management details with AO fracture type.

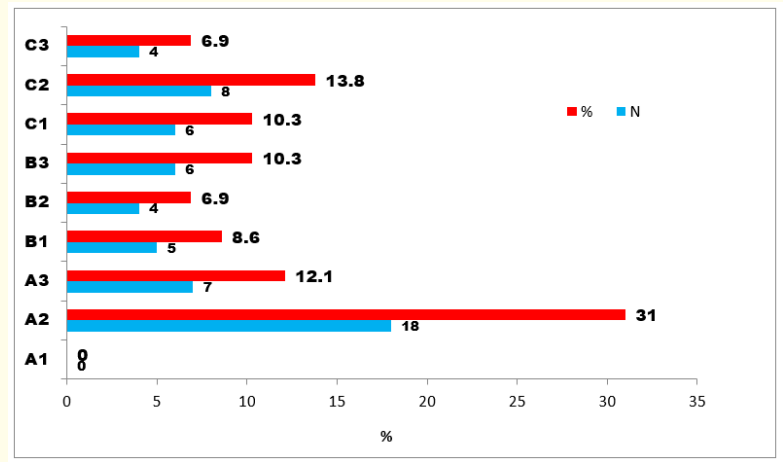

Figure 1: Distribution of study population as per the AO classification.

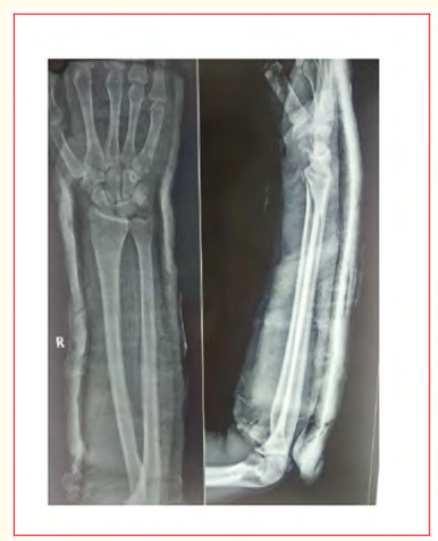

Figure 2: Pre operative X RAY.

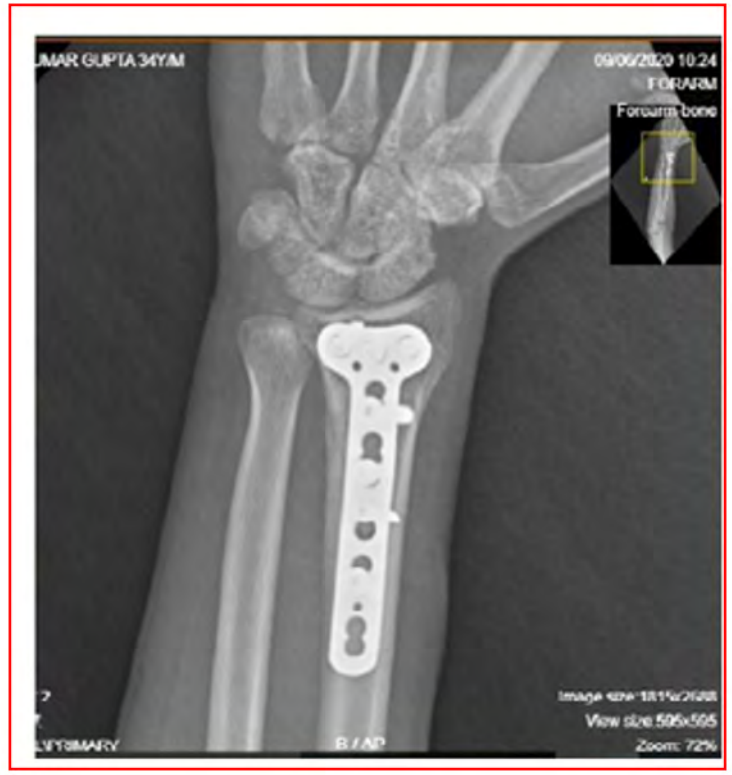

Figure 3: Post operative X ray.

quired in fully articular fractures. The external fixation 7 (18.42\%, odds $2.85 \mathrm{p}<0.001$ ) cases that shows statistically significant ( $\mathrm{p}$ $<0.01$ ). Outcome was recodered during follow up, the excellent to good outcome was seen in (42.9\%) cases managed by external fixation alone while fair to poor outcome was seen in $(28.6 \%)$ that 
found to be statistically significant $(\mathrm{p}<0.01)$. In the 2 cases with poor outcome $(28.6 \%) \mathrm{p}>0.01$, one had mal-union and other had radio-carpal arthritis. Overall, (72.4\%) cases of distal radius were managed surgically, we had excellent to good outcome $(24.1 \%)$ and (3.4\%) fair to poor outcome. In case of AO Type B2 fracture type, plating was used for fixation, all cases shows excellent outcome (50\%), Good (25\%) and fair (25\%). So plate osteosynthesis has preferred surgical modality for AO type B2 fractures. Results showed that, the management and outcome details among AO Type C2fracture type. Good outcome was seen in external fixation and external fixation $+\mathrm{k}$ wiring + plating group fair outcome was seen more among plating, $\mathrm{K}$ wiring, external fixator, External Fixator $+\mathrm{k}$ wiring group, seeing overall results, external fixation is preferred method of fixation for $\mathrm{C} 2$ type of fractures according to present study. Out of the total 58 cases, complications were noted in 4 cases (Figure 1). One case each(1.7\%) had pin tract infection, radial nerve injury, mal-union and radio-carpal arthritis respectively. In case of AO A2 fracture type, the patients were treated with Plating or $\mathrm{K}$ wiring. We recorded that, the excellent to good outcome is same in both plating and $\mathrm{K}$ wire fixations. This study shows plating and $\mathrm{K}$ wiring as preferred method for fixation in $\mathrm{A} 2$ type fractures. Similarly, AO Type A3 fracture type, cases were treated with plating or $\mathrm{K}$ wiring or external fixation. Excellent to good outcome were more inpatients treated with $\mathrm{K}$ wiring $(50 \%)$ or external fixator (50\%), So this study shows better outcome of $\mathrm{K}$ wiring or external fixation. AO Type B1 fracture type, all patients were treated with plating or K wiring. Plating modality have shown Excellent (50\%) and Good (50\%) outcomes were seen in k wiring, Hence, plating is preferred for B1 type of fractures according to present study. B2 and B3 subtypes of AO classification of distal radius fractures, only Plating was done in this intervention. So Plating will be preferred surgical modality for AO - B2 and B3 type of fractures according to present research findings. AO Type $\mathrm{C} 1$ fracture type. Patients were treated with plating or $\mathrm{K}$ wiring or external fixation $+\mathrm{K}$ wiring, an excellent outcome was seen only in plating group. So plating is preferred method of fixation over K wiring or external fixation + K wiring for C1 type of fractures in this study. AO Type C2 fracture type. Patients were treated with plating or $\mathrm{K}$ wiring or external fixator or external fixation $+\mathrm{K}$ wiring or external fixation $+\mathrm{K}$ wiring + plating. Good outcome was seen in external fixation and external fixation $+\mathrm{k}$ wiring + plating group fair outcome was seen more among plating, K wiring, external fixator, external fixator $+\mathrm{k}$ wiring group, seeing overall results, external fixation would be preferred method of fixation for C2 type of fractures according to present study.AO Type C3 fracture type. Patients were treated with plating or external fixator or external fixation $+\mathrm{K}$ wiring+ plating. Fair outcome was seen in plating and external fixation $+\mathrm{k}$ wiring + plating group and poor outcome in external fixation group, So plating or external fixation $+\mathrm{k}$ wiring+ plating is preferred method of fixation for C3 type of fractures according to present study. Excellent to good outcome was seen in (73.5\%) cases managed by plating while fair to poor outcome was seen in $26.5 \%$ and $0 \%$ cases respectively. Excellent to good outcome was seen in $76.9 \%$ cases managed by closed reduction and k-wire while fair to poor outcome was seen in $23.1 \%$ and $0 \%$ cases respectively. Excellent to good outcome was seen in $42.9 \%$ cases managed by external fixation alone while fair to poor outcome was seen in $28.6 \%$ cases each respectively. In the 2 cases with poor outcome (28.6\%), one had mal-union and other had radio-carpal arthritis. In the two cases managed external fixation and k-wire, 1 had good outcome while other had fair outcome (due to development of pin tract infection) (Figure 3). In the two cases managed external fixation, plating along with k-wiring, 1 had good outcome while other had fair outcome (due to radial eve injury).Overall, $72.4 \%$ cases of distal radius who were managed surgically had excellent to good outcome while $24.1 \%$ and $3.4 \%$ had fair to poor outcome respectively. Excellent to good outcome was observed to be associated with extraarticular radius fractures while fair outcome was seen in cases of articular fractures (Figure 2 ). Both the cases of poor functional outcome were of multi fragmentary articular fractures. One of them had mal-union while her developed radio carpal arthritis .Out of the total 58 cases, complications were noted in 4 cases. All of them were cases of articular fractures, managed by external fixation. One case each $(1.7 \%)$ had pin tract infection, radial nerve injury, mal-union and radio-carpal arthritis respectively.

\section{Discussion}

Distal radius fractures contribute for around 20\% of all fractures seen in emergency departments 1 and has an incidence of $1: 10,000$ people and represent $16 \%$ of skeletal and $74 \%$ of forearm fractures [24,26,28,30]. Heightened awareness of the widening scope of distal end radius fractures has led to the emergence of a substantial change in concepts that rational treatment should incorporate. Important among these concepts is that functional recovery is directly proportional to the accuracy of skeletal restoration [31-33]. When a distal end radius fracture is complex or

Citation: Anil Chowdary., et al. "Evaluation of Various Modalities of Surgical Treatment of Distal End Radius Fractures in a Tertiary Hospital in Bangalore". Acta Scientific Orthopaedics 5.3 (2022): 67-75. 
unstable, it usually requires surgery to ensure the fracture stays reduced during the healing process [26-28]. The anatomical restoration of the distal radial joint articular surface is the rationale for operative treatment. Popular treatment options to distal end radius fracture is to surgically implant plates, screws, or pins to hold the bone fragments in place. Surgical implants are most often implanted on the volar or dorsal side of wrist, but common on volar aspect [29-31]. External -external fixation is appropriate for unstable, intra-articular, compound and/or comminuted fractures. Compared with external fixation, internal plating has the advantage of allowing early mobilization and less complications [32-34]. The biggest drawback of plates, is its potential effect of irritating tendons on it, causing tendinopathy and possible tendon rupture. Newly designed thinner profile plates decrease this complication. In present study, we aimed to compare the functional outcome after treatment of fracture distal end radius with various surgical modalities i.e. closed reduction and percutaneous K-wire fixation under C-arm guidance with post op cast immobilization, ligamentotaxis and stabilization with external fixator, open reduction and internal fixation with dynamic compression plate, locking compression plates and buttress locking compression plate. Study included a total of 54 cases operated for distal radius fractures with 58 wrists admitted in Orthopaedic wards and who come for post op follow up in orthopaedic OPD of our hospital. Functional outcome was assessed by using Demerit scoring system at the end of 6 or 12 months. Mean age of the patients in study group was 37.21 years with over half $(55.6 \%)$ of the cases were of 40 years or below. Male predominance $(88.9 \%)$ was seen in the study group with male to female ratio of 8:1.Most common presentation in other studies was between age group of 30 to 40 years with male predominance. In a similar study by Saraogi AA., et al. mean age of the study participants was 37 years with male to female ratio of 3.3:1. Maruthi., et al. in their study with 30 patients with the age group of 21-60 years, observed average age of 38 years with 17 males and 13 were female patients. Alamgir., et al. in a similar series, studied 15 patients, out of which 10 were males and 5 were females. Goyal R., et al. observed mean age as 39.16 years with $60 \%$ males to $40 \%$ females. Parshuram N., et al. in their study observed distal end radius fracture to be more common in the 30-50 years, with an average of 43.9 years with $70 \%$ males to $30 \%$ females. Male preponderance can be attributed to their involvement in heavy manual labour, outdoor activities and riding vehicles. Most common mode of injury was
RTA (road traffic accident) (57.4\%) followed by FOOSH (fall on outstretched hand) (42.6\%). Goyal R., et al. in their study also observed RTAs to be the major cause for distal radius fracture seen in over $66 \%$ cases. Parshuram N., et al. in another similar study also observed RTA to be the most common cause for distal radius fracture. Ayhan Kilic., et al. and Anakweetal RE., et al. also reported road traffic accidents to be most common injury mode followed by history of fall on outstretched hand. The results showed that most of the fractures occurred in young individuals are due to high energy trauma such as road traffic accident and fall on outstretched hand. Fractures in old individuals are due to trivial fall and usually will be extra articular. Out of the 58 cases, 25 cases $(43.1 \%)$ were intra-articular fractures (AO type A2/A3), 15 cases (25.9\%) were partially articular (AO type B1-3) while 18 cases (31\%)were of extra-articular fractures (AO type C1-C3). Out of total 58 cases, 91.4\% were closed fractures while $8.6 \%$ were open fractures. A total of $58.6 \%$ cases were managed by plating, $22.4 \%$ with closed reduction and K-wire while external fixation with or without plating/ Kwire was required in 19\% cases. Indications for operative intervention include: Displaced intra-articular fractures with (either of them), post reduction with below values: a) articular step of $>2$ $\mathrm{mm}, \mathrm{b}$ ) radial shortening of $>3 \mathrm{~mm}$ and; c) $>15$ degrees of sagittal plane angulation (as measured from the anatomical volar tilted position). Type of operative treatment was dependent on fracture anatomy. Augmented external fixation with ligamentotaxis was indicated in non-articular irreducible displaced fractures; articular, displaced fractures which were reducible but unstable; irreducible and complex fractures (A.O. Type - A3, C2, C3). Trans-fixation with $\mathrm{k}$-wire and cast immobilization was done for non-articular displaced reducible but unstable fracture and articular displaced reducible and stable fractures (A.0. Type - A2,A3, B1, C1, C2). Internal fixation with plates was used in all fracture types. In present study, $72.4 \%$ cases of distal radius who were managed surgically (plating/ k-wire/ext. fixation) had excellent to good outcome while $24.1 \%$ and $3.4 \%$ had fair to poor outcome respectively. Excellent to good outcome was observed to be associated with extra-articular radius fractures while fair outcome was seen in cases of articular fractures. Both the cases of poor functional outcome were of multifragmentary articular fractures. One of them had mal-union while other developed radio carpal arthritis. An advantage of open reduction and internal fixation (ORIF) by compression plating is the early mobilisation. Early rehabilitation enables quick return to 
daily activites. In present study; excellent to good outcome was seen in $73.5 \%$ cases managed by plating while fair to poor outcome was seen in $26.5 \%$ and $0 \%$ cases respectively. Kwan K., et al. studied results following surgery with 2.4 -mm locking plate to distal radial fractures. An excellent to good result was obtained in $98 \%$ and $96 \%$ of patients according to the Gartland and Werley, and modified Green and O'Brien scores, respectively. Saraogi AA., et al. in their study observed $63.3 \%$ excellent results with plating group with no case of poor outcome. Khan SM., et al. (2016) observed that volar plate fixation of unstable distal end radius fracture provides a stable construct, which helps in early mobilization, hence better functional outcomes and minimizes chances of delayed or malunion and, thereby is an upcoming method of choice for fracture distal end of radius. Is a pure W., et al. in their study observed that the clinical outcome of the wrist joint was better in patients treated with locking compression plate (LCP) (93.3\%) than percutaneous K-wires and external fixation. Better treatment outcome, better wrist range of movements and resumption of normal activities was noted for patients treated with locking compression plate (96\%) than percutaneous fixation with K-wires and external fixation. There is no difference in functional outcome inpatients with dorsally displaced fractures of the distal radius treated with Kirschner wires or volar locking plates. Study showed significantly higher risk of infection in EF group. Incidence of malunion and median nerve dysfunction were similar in both groups. In a similar metaanalysis, Fu Q., et al. reported that plating is advantageous over external fixation by analysing the DASH scores, maintenance of ulnar variance, and total and mild surgical complications at 12 months. $\mathrm{K}$-wire Closed reduction and percutaneous Kirschner wires (Kwire) fixation with plaster immobilization is one of the commonest treatment method employed in the management of distal end radius fracture. Being an less invasive and a technically less demanding procedure compared with ORIF, it's also more economical than ORIF. In present study, trans-fixation with k-wire and immobilization in cast was treatment method for non-articular displaced reducible but unstable fracture and articular displaced reducible and stable fractures (A.O. Type - A2, A3, B1, C1, C2). We observed excellent to good outcome in $76.9 \%$ cases while fair to poor outcome was seen in $23.1 \%$ and $0 \%$ cases respectively. Adawy AL., et al. in their study observed 70 cases of closed distal radius fracture. A total of 36 (51.4\%) cases got excellent score, 18 (25.7\%) cases were good, $12(17.1 \%)$ cases were fair, and four $(5.7 \%)$ cases were poor.
All patients managed by k-wire had a good to excellent range of motion regarding forearm rotation, and around $80 \%$ had good to excellent range of motion regarding flexion or extension of their wrist [15]. One patient had a pin tract infection, and another subcutaneous migration of a pin, both were treated by pin removal. Radiological and functional outcome in fractures of the distal end radius treated by percutaneous K-wire fixation. According to Mayo score $72.5 \%(n=29)$ of study patients had excellent to good outcome, where as $17.5 \%(n=7)$ had fair outcome and in $10 \%(n=4)$ outcome was poor. The most common early complications of distal radius fractures include median nerve injury, compartment syndrome, and vascular compromise (although the latter two rarely occur).Acute carpal tunnel syndrome (ACTS) is most commonly observed in seriously comminuted or displaced fractures, in multiple reduction patients, and in serious wrist bending fractures (> 15 degrees) [37]. At the original and first follow-up visits, and at the initial visits after any re-manipulation, the clinician must conduct a thorough neurological examination searching for signs of Actions. The most crucial result is weakness or loss of thumb or index finger flexion. If symptoms progress, with or without reduction, or if surgical fixation is planned, carpal tunnel release is indicated. If releases are carried out urgently, outcomes are best. A minor sensory deficit associated with median contusion of the nerve is frequently found and is not triggered by Actions in general. The most crucial result is weakness or loss of thumb or index finger flexion. If symptoms progress, with or without reduction, or if surgical fixation is planned, carpal tunnel release is indicated. If releases are carried out urgently, outcomes are best. A minor sensory deficit associated with median contusion of the nerve is frequently found and is not triggered by actions in general. In closed fractures, vascular injuries are uncommon, but in high-energy injuries with severe fracture displacement, injury to the radial or ulnar artery has been recorded. Perfusion often improves with reduction, but for any recurrent disability, emergent vascular surgery assessment is required. Carpal bone and carpal ligament injuries occasionally accompany distal radius fractures, and despite appropriate alignment, they should be suspected in patients with persistent wrist pain. A case series of 565 Colles fractures showed scaphoid fractures in 0.7 percent of cases and intercarpal ligament injuries in 0.9 percent of cases were initially overlooked. Skin tearing may occur with over-vigorous manual reduction and also with these of older, metal finger traps. Complications of closed reduction and cast treatment For the newer fabric finger traps, the skin rarely tears. 
Cloth tape may be placed over the fingers until they are hanged to decrease skin damage if metal skin traps are used. Closed extremity fractures put patients at risk of developing compartment syndrome, while distal radius fractures are a rare complication [3739]. Compartment syndrome patients complain of increasing or constant serious pain and paraesthesia. Increasing analgesic use may be one possible warning sign. Generally, through passive extension of the fingertips, the clinician can palpate a firm, stressed forearm, which can elicit pain, thereby stretching the flexor tendons inside the forearm compartment. Measuring elevated compartment pressures allows for more detailed diagnosis. Natural pressure is less than $5 \mathrm{mmHg}$; typically, pressure greater than 30 mmHg warrants emerging fasciotomy. Capillary refill alterations, distal pulses, and skin tone are NOT accurate outcomes. Clinicians should advise patients about and consider the signs of compartment syndrome in patients who complain of intense pain in the days immediately after fracture reduction. There are reports of closed reduction compartment syndrome under local hematoma block, but this is a rare complication, and the function of hematoma block has not been demonstrated [39]. There have also been cases of Staphylococcus aureus osteomyelitis following hematoma block. These risks should be avoided by paying attention to sterile procedures and the volume of local anaesthetic injected. Splinting of the wrist by more than 15 degrees of palmar flexion raises the likelihood of ACTS and complex regional pain syndrome [40]. To avoid MCP joint contractures and proximal tendon adhesions, careful splinting that allows complete flexion and extension of the metacarpal phalangeal (MCP) joints is necessary Due to median nerve contusion at the time of injury or decrease, persistent sensory neuropathy following distal radius fracture can occur, but it closely correlates with fracture malunion. For chronic symptoms, surgical treatment with osteotomy and/or release of the median nerve is indicated. Inflammation and rupture of the tendon may happen with closed cast therapy $[41,42]$. Rupture of the tendon of the extensor pollicis longus (EPL) is most common with an occurrence of $0.3 \%$ to $3 \%[43,44]$, and occurs after injury between two weeks and11 months (average seven weeks).43 After rupture, diagnosis is generally made, and treatment is surgical. With minimally displaced fractures, EPL breakage is more common [46]. After the distal radius fracture, tendonitis of the first dorsal compartment and of the extensor carpi ulnaris can also be observed. Typically, this is susceptible to steroid injection, but it must be separated from triangular fibrocartilage tear or other ligamentous ulnocarpal injury.

\section{Conclusion}

The goal for treatment of the distal end of the radius fractures is fully functional recovery of the wrist and prerequisites are restoration of the anatomy, articular congruity and early mobilization. Extra-articular fractures give better results compared to intraarticular fractures. Functional outcome in distal radius fractures is dependent on patient 'sage, fracture anatomy, displacement, reducibility, stability and articular incongruity of fractures. Functional outcomes are related more to the quality of anatomical reduction than to the method of immobilization. Locking compression plate is a safe and effective treatment for distal radius.

Unstable fractures. It also stabilizes dorsally displaced unstable distal radius fractures with least complications. Specially locking implants give advantages in the surgical treatment of distal end radius fractures with metaphysical combination (A3 and $\mathrm{C} 2$ fractures).External fixation with supplemental pin/ plate fixation, is however the preferred option in cases of intra-articular fractures. Present study shows better outcomes with plating and $\mathrm{K}$ wiring for A2 type of fractures, K wiring or External fixation in AO Type A3 fracture. Plating over $\mathrm{K}$ wiring for B1 type, Plating for B2 and B3 types. Plating is preferred method of fixation for C1 type of fractures, followed by $\mathrm{K}$ wiring then External fixation $+\mathrm{K}$ wiring. External fixation was preferred method compared to all other modalities for C2type.Plating or External Fixation + $\mathrm{k}$ wiring+ plating is preferred method of fixation for C3 type of fractures according to present study. Due to complexity of AO C2 and C3 fracture types, outcome results were limited irrespective of fixation method used.

\section{Bibliography}

1. Belloti JC., et al. "Are distal radius fracture classificationsreproducible; Intra and interobserver agreement". Sao Paulo Medical Journal - SciELO 126.3 (2008): 180-185.

2. Diaz-Garcia RJ., et al. "A systematic review ofoutcomes and complications of treating unstable distal radius fractures in theelderly". The Journal of Hand Surgery 36.5 (2011): 824-835.

3. Chung KC., et al. "Trends in the United States in thetreatment of distal radial fractures in the elderly". Journal of Bone and Joint Surgery American 91.8 (2009): 1868-1873.

4. Lidström A. "Fractures of the distal end of the radius: a clinical and statisticalstudy of end results". Acta Orthopaedica Scandinavica 30.41 (1959): 1-18. 
5. Lafontaine M., et al. "Stability assessment of distal radiusfractures”. Injury 20.4 (1989): 208-210.

6. Colles A. "On the fracture of the carpal extremity of the radius". Edinburgh Medical and Surgical Journal 10 (1814): 181.

7. Bohler L. "The treatment of fracture". New York, Grune and Stratton (1932): 90-96.

8. Rajan S., et al. "Radiological and functional outcome in extraarticular fractures oflower end radius treated conservatively with respect to its position ofimmobilization". The Indian Journal of Orthopaedics 42.2 (2008): 201-207.

9. Anderson R and O'Neil G. "Comminuted fractures of the distal end of the radius". Surgery, Gynecology and Obstetrics 78 (1944): 434-440.

10. John T Anderson., et al. "Buhr Complications of TreatingDistal Radius Fractures with External Fixation: A Community Experience Iowa". Journal of Orthopaedics 24 (2004): 53-59.

11. Grana WA and Kopta JA. "The Roger Anderson device in the treatment of fractures ofthe distal end of the radius". Journal of Bone and Joint Surgery 61.8 (1979): 1234-1238.

12. Gartland JJ Jr and Werley CW. "Evaluation of healed Colles' fractures". Journal of Bone and Joint Surgery 33-A.4 (1951): 895-907.

13. DePalma AF. "Comminuted fractures of the distal end of the radius treated byulnar pinning". Journal of Bone and Joint Surgery 24-A-3 (1952): 651-662.

14. Dowling JJ and Sawyer B Jr. “Comminuted Colles' fractures. Evaluation of a methodof treatment". Journal of Bone and Joint Surgery 43-A (1961): 657-668.

15. Thomas FB. "Reduction of Smith's fracture". The Journal of Bone and Joint Surgery British 39-B.3 (1957): 463-470.

16. Scheck M. "Long-term follow-up of treatment of comminuted fractures of thedistal end of the radius by transfixation with Kirschner wires and cast". The Journal of Bone and Joint Surgery American 44-A (1962): 337-351.

17. Ellis J. "Smith's and Barton's fractures. A method of treatment". The Journal of Bone and Joint Surgery British 47.4 (1965): 724727.

18. Smaill GB. "Long-term follow-up of Colles's fracture”. The Journal of Bone and Joint Surgery British 47 (1965): 80-85.
19. Frykman G. "Fracture of the distal radius including sequelae-shoulder-hand-fingersyndrome, disturbance in the distal radio-ulnar joint and impairment of nervefunction. A clinical and experimental study". Acta Orthopaedica Scandinavica 108 (1967): 3.

20. Pool C. "Colles's fracture. A prospective study of treatment". The Journal of Bone and Joint Surgery. British 55.3 (1973): 540544.

21. Sarmiento A., et al. "Colles' fractures. Functionalbracing in supination". The Journal of Bone and Joint Surgery American 57.3 (1975): 311-317.

22. Green DP. "Pins and plaster treatment of comminuted fractures of the distal end ofthe radius". The Journal of Bone and Joint Surgery American 57.3 (1975): 304-310.

23. Cooney WP., et al. "External pin fixation for unstableColles' fractures". The Journal of Bone and Joint Surgery American 61.6 (1979): 840-845.

24. Van Der Linden W., et al. "How should its displacement be measured and how should it be immobilized?" The Journal of Bone and Joint Surgery American 63.8 (1981): 1285-1288.

25. Melone CP Jr. "Open treatment for displaced articular fractures of the distal radius". Clinical Orthopaedics and Related Research 202 (1986): 103-111.

26. Foster DE and Kopta JA. "Update on external fixators in the treatment of wristfractures". Clinical Orthopaedics and Related Research 204 (1986): 177-183.

27. Altissimi M., et al. "Long-term results ofconservative treatment of fractures of the distal radius". Clinical Orthopaedics and Related Research 206 (1986): 202-210.

28. Clyburn TA. "Dynamic external fixation for comminuted intraarticular fractures of the distal end of the radius". The Journal of Bone and Joint Surgery American 69.2 (1987): 248-254.

29. Keating JF., et al. "Internal fixation of volar-displaced distal radial fractures". The Journal of Bone and Joint Surgery British 76.3 (1994): 401-405.

30. Fitoussi F., et al. "Treatment of displaced intra-articular fractures of the distal end of the radius with plates". The Journal of Bone and Joint Surgery American 79.9 (1997): 1303-1312.

31. Kaempffe FA and Walker KM. "External fixation for distal radius fractures: effect of distraction on outcome". Clinical Orthopaedics and Related Research 380 (2000): 220-225. 
32. Emami A and Mjöberg B. "A safer pin position for external fixation of distal radial fractures". Injury 31.9 (2000): 749-750.

33. Rogachefsky RA., et al. "Treatment of severely comminuted intra-articular fractures of thedistal end of the radius by open reduction and combined internal and externalfixation". The Journal of Bone and Joint Surgery American 83-A.4 (2001): 509-519.

34. Murray PM and Trigg SD. "Treatment of distal radius fractures with external fixation: technical considerations for rehabilitation". Techniques in Hand and Upper Extremity Surgery 6.4 (2002): 213-218.

35. Drobetz $\mathrm{H}$ and Kutscha-Lissberg E. "Osteosynthesis of distal radial fractures with avolar locking screw plate system". International Orthopaedics 27.1 (2003): 1-6.

36. Ring D., et al. "Combined dorsal and volar plate fixation of complex fractures of the distal part of the radius". The Journal of Bone and Joint Surgery American 86-A.8 (2004): 1646-1652.

37. Kreder HJ., et al. "Indirect reduction and percutaneous fixation versus open reductionand internal fixation for displaced intra-articular fractures of the distal radius: arandomised, controlled trial". The Journal of Bone and Joint Surgery British 87.6 (2005): 829-836.

38. Kiliç A., et al. "[Volar locking plate fixation of unstable distal radius fractures]". Acta Orthopaedica et Traumatologica Turcica 43.4 (2009): 303-308.

39. Schmelzer-Schmied N., et al. "Comparison ofexternal fixation, locking and non-locking palmar plating for unstable distalradius fractures in the elderly". International Orthopaedics 33.3 (2009): 773-778.

40. Xu GG., et al. "Prospective randomised study ofintra-articular fractures of the distal radius: comparison between external fixationand plate fixation". Annals - Academy of Medicine Singapore 38.7 (2009): 600-606.

41. Gereli A., et al. "Comparison of palmarlocking plate and K-wire augmented external fixation for intra-articular andcomminuted distal radius fractures". Acta Orthopaedica et Traumatologica Turcica 44.3 (2010): 212-219.

42. Kwan K., et al. "Operative treatment of distal radial fractures withlocking plate system-a prospective study". International Orthopaedics 35.3 (2011): 389-394.
43. Wilcke MK., et al. "Wrist function recovers morerapidly after volar locked plating than after external fixation but the outcomes aresimilar after 1 year". Acta Orthopaedica 82.1 (2011): 76-81.

44. Diaz-Garcia RJ., et al. "A systematic review ofoutcomes and complications of treating unstable distal radius fractures in theelderly". The Journal of Hand Surgery 36.5 (2012): 824-835.

45. Tan V., et al. "Comparative analysis ofintramedullary nail fixation versus casting for treatment of distal radius fractures". The Journal of Hand Surgery 3 (2012): 460-468.

46. Phadnis J., et al. "Midterm functional outcome after the internal fixation of distal radius fractures". Journal of Orthopaedic Surgery and Research 7.1 (2012): 126.

47. Isapure W. "Fracture fixation of distal part of the radius: a comparative study ofdifferent method". IOSR Journals 14.2 (2015): 05-07.

48. Costa M., et al. "Percutaneousfixation with Kirschner wires versus volar locking plate fixation in adults withdorsally displaced fracture of distal radius: randomised controlled trial". British Medical Journal 349.2 (2014): g4807-g4807.

\section{Assets from publication with us}

- Prompt Acknowledgement after receiving the article

- Thorough Double blinded peer review

- Rapid Publication

- Issue of Publication Certificate

- High visibility of your Published work

Website: www.actascientific.com/

Submit Article: www.actascientific.com/submission.php

Email us: editor@actascientific.com

Contact us: +919182824667 